\title{
Identification and preclinical evaluation of the small molecule, NSC745887, for treating glioblastomas via suppressing DcR3- associated signaling pathways
}

\author{
Li-Yun Fann ${ }^{1,2,6}$, Ying Chen ${ }^{1,3}$, Da-Chen $\mathrm{Chu}^{2}$, Shao-Ju Weng ${ }^{3}$, Heng-Cheng $\mathrm{Chu}^{4}$, \\ Alexander T.H. Wu ${ }^{5}$, Jiann-Fong Lee ${ }^{6}$, Ahmed Atef Ahmed Ali ${ }^{6}$, Tsung-Chih Chen ${ }^{6}$, \\ Hsu-Shan Huang ${ }^{1,3,6}$ and Kuo-Hsing $\mathrm{Ma}^{1,3}$ \\ ${ }^{1}$ Graduate Institute of Medical Sciences, National Defense Medical Center, Taipei, Taiwan, ROC \\ ${ }^{2}$ Department of Nursing and Department of Neurosurgery, Taipei City Hospital, Taipei, Taiwan, ROC \\ ${ }^{3}$ Department of Biology and Anatomy, National Defense Medical Center, Taipei, Taiwan, ROC \\ ${ }^{4}$ Department of Internal Medicine, School of Medicine, College of Medicine, Taipei Medical University, Taipei, Taiwan, ROC \\ ${ }^{5}$ The PhD Program for Translational Medicine, College of Medical Science and Technology, Taipei Medical University, Taipei, \\ Taiwan, ROC \\ ${ }^{6}$ Graduate Institute for Cancer Biology and Drug Discovery, College of Medical Science and Technology, Taipei Medical \\ University, Taipei, Taiwan, ROC \\ Correspondence to: Kuo-Hsing Ma, email: kuohsing91@yahoo.com.tw \\ Hsu-Shan Huang, email: huanghs99@tmu.edu.tw \\ Keywords: Naphtho [2,3-f] quinoxaline-7, 12-dione; decoy receptor 3 (DCR3); [ $\left.{ }^{18} \mathrm{~F}\right]-\mathrm{FDG}$; animal-PET
}

Received: July 19,2017 Accepted: December 11, 2017～Published: December 27, 2017

Copyright: Fann et al. This is an open-access article distributed under the terms of the Creative Commons Attribution License 3.0 (CC BY 3.0), which permits unrestricted use, distribution, and reproduction in any medium, provided the original author and source are credited.

\section{ABSTRACT}

The small-molecule naphtha [2,3-f]quinoxaline-7,12-dione (NSC745887) can effectively inhibit the proliferation of various cancers by trapping DNA-topoisomerase cleavage. The aim of this study was to elucidate cellular responses of NSC745887 in human glioblastoma multiforme (GBM, U118MG and U87MG cells) and investigate the underlying molecular mechanisms. NSC745887 reduced the cell survival rate and increased the sub- $G_{1}$ population in dose- and time-dependent manners in GBM cells. Moreover, NSC745887 increased expression of YH2AX and caused DNA fragmentation leading to DNA damage. Furthermore, Annexin V/propidium iodide and $\mathrm{Br}-\mathrm{dTP}$ staining showed the apoptotic effect of NSC745887 in GBM cells. DNA repair proteins of ataxia-telangiectasia mutated (ATM), ATM and Rad3-related, and decoy receptor 3 also decreased with NSC745887 treatment. In addition, NSC745887 caused apoptosis by the caspase-8/9-caspase-3-poly(ADP-ribose) polymerase cascade. An in vivo study indicated that NSC745887 suppressed the $\left[{ }^{18} \mathrm{~F}\right]-\mathrm{FDG}-s p e c i f i c$ uptake value in brain tumors. Histological staining also indicated a decrease in Ki-67 and increases in YH2AX and cleaved caspase- 3 in the brain tumor area. These data provide preclinical evidence for NSC745887 as a potential new small molecule drug for managing glioblastomas.

\section{INTRODUCTION}

Glioblastoma multiforme (GBM) is a therapeutic challenge because it is a hard-to-treat and aggressive brain tumor and one of the most deadly forms of primary brain neoplasms [1]. A therapeutic objective is sorely needed to target GBM, a notoriously treatment-resistant brain cancer. Furthermore, the central nervous system (CNS) and the pathogenesis of GBM are complex, and much remains to be learned about putative key signaling pathways before they can be therapeutically exploited. An interplay between metabolic and oncogenic processes in brain tumors is driven by several signaling pathways that are differentially activated or silenced with both parallel and converging complex interactions [2]. Most importantly, human malignant glioma cells were engineered to release 
high amounts of Decoy receptor 3 (DcR3), which is overexpressed in the lungs and gastrointestinal tract $[3,4]$ and is associated with DcR3 binding to the fatty acid synthetase ligand (FasL) and inhibition of FasL-induced apoptosis [5]. It is noteworthy that DcR3 holds promise as a new target for treating gliomas, but still little is known regarding the molecular mechanisms underlying the smallmolecule inhibitor of DcR3.

In view of unmet and urgent clinical needs, we were motivated by [our?] recent data from the National Cancer Institute (NCI) indicating that the CNS might respond to GBM as novel anti-glioblastoma therapeutics [6]. Several compounds were selected by the NCI for a one-dose screening program and further studies on NSC745887 where the curves cross these lines represent the interpolated values to cause $50 \%$ growth inhibition $\left(\mathrm{GI}_{50}\right)$, total growth inhibition (TGI), and $50 \%$ cell killing $\left(\mathrm{LC}_{50}\right)$, respectively (Supplementary Tables 1-3 in Supplementary Information). To date, only five drugs have been approved by the US FDA to treat brain tumors: everolimus, bevacizumab, carmustine (BCNU), lomustine (CCNU), and temozolomide (TMZ) [7]. Thanks to our innovative techniques in drug discovery and preliminary studies $[8,9]$, we developed a series of tetraheterocyclic homologues that showed exceptional potencies against several types of cancer [9-14]. From this class of compounds, NSC745887 is a naphtho[2,3-f]quinoxaline7,12-dione (Figure 1) that exhibited a unique multilog differential pattern of activity in our earlier study [9]. To address this efforts were directed toward a synthetic small molecule (NSC745887), which exhibited unprecedented abilities such as cell-cycle regulation, and induction of apoptosis, senescence, and DNA damage in human glioblastoma cells. We also investigated the important molecular mechanisms responsible for the anticancer effects of NSC745887 against human GBM cells in vitro and in a xenograft animal model.

All tumors can be detected based on tracer techniques, because $\left[{ }^{18} \mathrm{~F}\right]$-fluorodeoxyglucose $\left(\left[{ }^{18} \mathrm{~F}\right]-\mathrm{FDG}\right)$ is a glucose analogue that is significantly taken up by glioma cells relative to normal cells [15]. With the very commonly used animal positron emission tomography (animal-PET), each nude mouse was subjected to an $\left[{ }^{18} \mathrm{~F}\right]-\mathrm{FDG}$ scan, and tumor metastasis was monitored with an in vivo dynamic imaging system. In this study owing to potential falsepositives introduced by possible accumulation of $\left[{ }^{18} \mathrm{~F}\right]$ FDG in tumor cells, PET imaging was applied to improve the accuracy. The continually evolving field of examining the mechanism of GBM inhibition has prompted a morerational use of targeted small-molecule anti-glioblastoma agents. This study aimed to investigate the toxic effect of the small-molecule, NSC745887, on GBM cell lines and the underlying mechanisms using both bioinformatics and cellbased approaches. NSC745887 exhibited potent cytotoxic and proapoptotic effects on GBM cells in dose- and timedependent manners. Notably, NSC745887 treatment promoted $\mathrm{G}_{2} / \mathrm{M}$ arrest and induced apoptosis mainly via inducing DNA damage response signaling in human GBM cells. Accordingly, DcR3 in gliomas was significantly upregulated compared to normal brain tissues [5]. However, the effect of the DcR3-specific small molecule on the cell biology of glioma cells remains incompletely understood. More importantly, NSC745887 significantly induced expressions of mitochondrion-mediated proapoptotic proteins via DcR3 suppression which enhanced cell death surface receptor Fas binding to FasL that resulted in apoptotic cell death, as mediated by caspase activation. Most small-molecule anticancer drugs in use today target DNA and are part of the cellular DNA damage response (DDR) network [16]. Small-molecule inducers of the DDR pathway are of great interest, and several are under clinical development. However, the specificity of the targets and the biological roles of the phosphorylation pathway in the DDR and intricate series of interlocking mechanisms induced by NSC745887 are not known. DcR3 and DDR cancer therapy represent very attractive approaches, and potential adjuvants to standard GBM therapy are worth exploring [17-19]. Our current findings demonstrated that NSC745887mediated GBM inhibitory effects were associated with DcR3 inhibition. More importantly, NSC745887 treatment suppressed GBM tumorigenesis in both p53 wild-type and mutant forms. This advantage may serve a broader spectrum of GBM patients in managing this malignancy in future clinical settings.<smiles>Nc1ccc2c(c1N)C(=O)c1ccccc1C2=O</smiles><smiles>CCC(C)=O</smiles><smiles>O=C1c2ccccc2C(=O)c2c1ccc1nccnc21</smiles>

NSC745887 


\section{RESULTS}

\section{Cytotoxicity of NSC745887 towards U118MG and U87MG cells}

NSC745887 was synthesized according to our previous study (Figure 1 please refer to Supplementary Figure 1 for more information on chemical synthesis and analysis) [9]. First, in order to explore the cytotoxicity of NSC745887, human glioblastoma cells (U118MG and U87MG) were treated with NSC745887 for 24,48 , and $72 \mathrm{~h}$, and the cytotoxic effects were evaluated via an MTT assay. Cell morphological changes were observed with a light microscope, and significantly decreased expression of Ki-67 was found using a Western blot analysis. As shown in Figure 2 and Supplementary Figure 2, NSC745887 inhibited the proliferation of both U118MG and U87MG cells, and the cytotoxic effects were specific. To evaluate the dose- and time-dependent effects on cell viability, we performed an MTT assay after exposure of U118MG and U87MG cells to different concentrations of NSC745887 for 24, 48, and $72 \mathrm{~h}$ (Figure 2A). U118MG cells began to undergo apoptosis at about $24 \mathrm{~h}$ after treatment with $10 \mu \mathrm{M}$ NSC745887, and more than $80 \%$ of cells had undergone apoptosis after $48 \mathrm{~h}$. U87MG cells displayed signs of apoptosis after $24 \mathrm{~h}$ at $10 \mu \mathrm{M}$, and more than $80 \%$ of cells had undergone apoptosis after $72 \mathrm{~h}$. Our data suggested that U118MG and U87MG cells are sensitive to NSC745887. Characteristic morphological features of apoptotic cells included shrinkage of the cell volume and membrane-bound apoptotic bodies that prominently appeared following treatment of cells with NSC745887 (Figure 2B). Next, we observed expressions of Ki-67 in both GBM cell lines using immunoblotting; vinculin was used as a loading control [20,21]. Even though Ki-67 is strongly associated with tumor cells and is a marker of cell proliferation, we found that the Ki-67 level was strongly suppressed in U118MG cells treated with NSC745887. Similar observations were seen in U87MG cells (Figure 2C). These results are consistent with previous reports and suggest that NSC745887 causes apoptosis in U118MG and U87MG cells.

\section{NSC745887 induces dose- and time-dependent apoptosis and GBM cell-cycle arrest in the $G_{2} / M$ phase}

In order to further investigate the underlying mechanisms of NSC745887, cell-cycle patterns of U118MG and U87MG cells subjected to different doses of NSC745887 for 24 and $48 \mathrm{~h}$ were scrutinized. We performed a flow cytometric analysis of PI-stained cells to study cell-cycle progression after treatment with NSC745887. Cell-cycle populations of GBM cells were compared at 24 and $48 \mathrm{~h}$ after treatment with various concentrations of NSC745887 as shown in Figure 3 and Supplementary Figure 3 in the Supplementary Information. NSC745887 effectively caused increased cell-cycle arrest in the $\mathrm{G}_{2} / \mathrm{M}$ phase with higher concentrations and longer durations, and the proportion of hypodiploid cells increased in dose- and time-dependent manners. More specifically, even though the ratio of cells in the sub- $\mathrm{G}_{1}$ phase was obviously higher, accumulation of cells in the $\mathrm{G}_{2} / \mathrm{M}$ phase resulted in apoptosis. In U118MG cells, as illustrated in Figure $3 \mathrm{~A}$ and $3 \mathrm{~B}$, proportions of cells in the sub- $\mathrm{G}_{1}$ phase, which had the appearance of apoptosis, had increased to $26.6 \%$ and $40.2 \%$ at $24 \mathrm{~h}$ after treatment with 10 and $15 \mu \mathrm{M}$ of NSC745887, and were elevated to $69.8 \%$ and $76.5 \%$ at $48 \mathrm{~h}$ after treatment, respectively. U87MG cells also showed similar results at the sub- $\mathrm{G}_{1}$ phase (Figure $3 \mathrm{C}, 3 \mathrm{D}$ ). Moreover, in U87MG cells, NSC745887 increased the percentage of cells in the $\mathrm{G}_{2} / \mathrm{M}$ phase while decreasing the $\mathrm{G}_{1}$ fraction (Figure 3E). Our data suggest that NSC745887 induced apoptosis and $\mathrm{G}_{2} / \mathrm{M}$ cell-cycle arrest. Although both cell lines (U118MG and U87MG) responded to NSC745887 treatment, U118MG cells were more sensitive to NSC745887 than were U87MG cells. Proportions of cells with 4N DNA content, which indicates $\mathrm{G}_{2} / \mathrm{M}$ blockage, showed increases of $27.5 \%$ and $31.8 \%$ in cells respectively treated with 10 and $15 \mu \mathrm{M}$ of NSC745887 (Figure 3E), suggesting that NSC745887 can cause $\mathrm{G}_{2} / \mathrm{M}$ arrest in GBM cells. These results suggested that NSC745887 caused apoptosis of GBM cells in doseand time-dependent manners.

\section{Induction of morphological and biochemical features of apoptosis after NSC745887 treatment}

Biochemical features of apoptosis were examined using a flow cytometric analysis and confocal microscopic imaging (Figure 4, Supplementary Figure 4 in Supplementary Information). Apoptosis was originally defined by structural alterations in cells observable by transmitted light and electron microscopy [19, 22]. Annexin V-conjugated PE- and 7 AAD-stained cells showed features of apoptosis after NSC745887 treatment in dose- and time-dependent manners in both the U118MG and U87MG cell lines (Figure 4A). An increase in populations of Annexin V PE-positive and 7AAD-negative or -positive cells in the A4 area indicated the occurrence of apoptosis, as shown in both U118MG and U87MG cell lines with various doses of NSC745887. Based on the flow cytometric analysis of Annexin V PE-positive cells, percentages of apoptotic cells in the U118MG and U87MG cell lines were determined (right panels of Figure 4A). Apoptosis rates without treatment, and with treatment with 10 or $15 \mu \mathrm{M} \mathrm{NSC} 745887$ for $24 \mathrm{~h}$ were $1.6 \%, 16.5 \%$, and $32.8 \%$ in U118MG cells and $3.2 \% 14.7 \%$, and $19.3 \%$ in U87MG cells, respectively. Compared to control cells, 10 $\mu \mathrm{M}$ NSC745887 very significantly increased percentages of Annexin V PE-positive populations in both cell lines. The increase in Annexin V PE-positive cells after NSC745887 treatment indicated a prominent biochemical feature of apoptosis in GBM cells. To verify apoptotic events in NSC745887-treated cells, phosphatidylserine of external membranes and nuclei of cells stained with 
Annexin V-FITC and PI were imaged by confocal microscopy. As shown in Figure 4B, the apoptotic program was characterized by condensation of the cytoplasm and nuclei in both treated cell lines. We then utilized a TUNEL assay, in which the TdT enzyme catalyzes a templateindependent addition of Br-dUTP to the 3'-hydroxyl $(\mathrm{OH})$ termini of double- and single-stranded DNA, to detect DNA damage events. Figure 4C shows results of the flow cytometric analysis of Br-dUTP-FITC/PI-stained $\mathrm{U} 118 \mathrm{MG}$ and $\mathrm{U} 87 \mathrm{MG}$ cells at $24 \mathrm{~h}$ after treatment with various concentrations of NSC745887. The upper right quadrant of the cytograms represents the number of cells exhibiting DNA fragmentation, which was positive for Br-dUTP binding and showed PI uptake. The apoptotic cell population of U118MG cells significantly increased

A

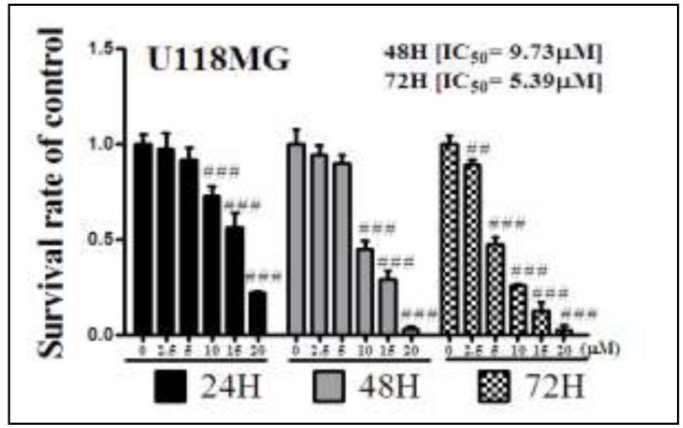

B U118MG

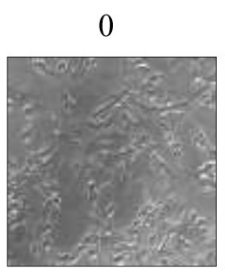

10

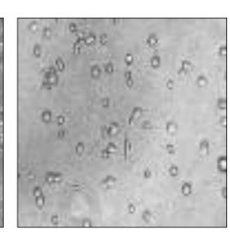

15

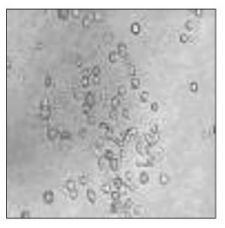

from $0.45 \%$ in untreated cells to $36.6 \%$ and $44.0 \%$ in 10 and $15 \mu \mathrm{M}$ NSC 745887-treated cells at $24 \mathrm{~h}$, respectively; also, proportions of U87MG cells with fragmented DNA content increased from $0.77 \%$ to $16.7 \%$. Overall, apoptosis emerged as the major mechanism of cell death promoted by NSC745887 in GBM cells.

\section{Impacts of ATM and ATR phosphorylation on NSC745887 sensitivity}

In our previous study, we reported that NSC745887 induced DNA damage caused by topoisomerase inhibition in HeLa cells [8]. The phosphorylated form of H2AX on serine139 [23], which mediates retention of double-strand DNA break (DSB)-responsive proteins on DSB-associated

$\mathrm{C}$

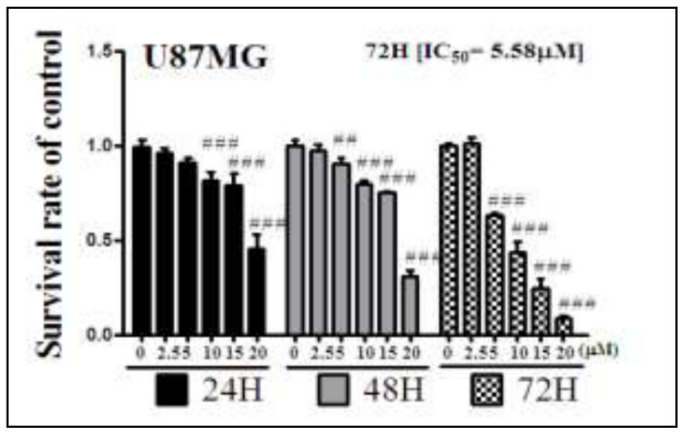

\section{U87MG}

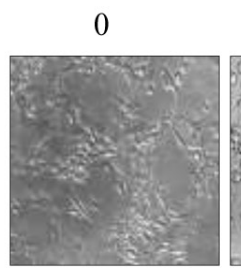

10

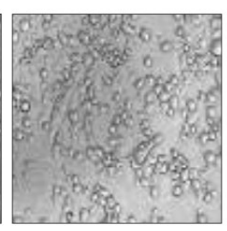

15

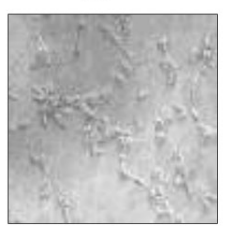

U118MG

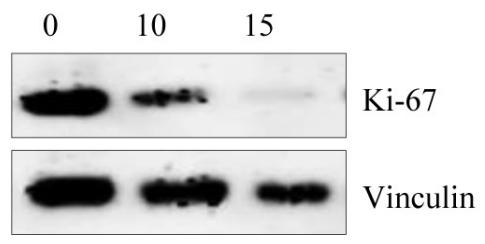

U87MG

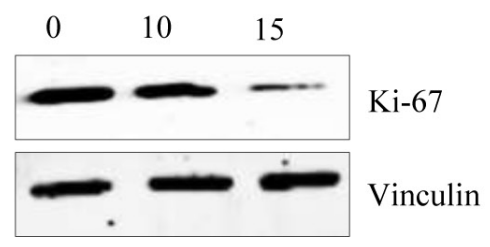

Figure 2: Cell cytotoxicity of NSC745887 upon treatment of U118MG and U87MG cells. (A) U118MG and U87MG cells were treated with NSC745887 at $0,2.5,5,10,15$, and $20 \mu \mathrm{M}$ for 24,48 , and $72 \mathrm{~h}$. Cells were subsequently subjected to a time-course assay. Cells were detected every $24 \mathrm{~h}$, and the cell survival rate was analyzed by an MTT assay. U118MG cells were observed to be more sensitive to NSC745887, as the percentage of apoptosis had already increased by $24 \mathrm{~h}$ after NSC745887 treatment. U87MG cells responded more slowly, and began to undergo some apoptosis about $24 \mathrm{~h}$ after treatment. (B) Microscopy also showed that after $24 \mathrm{~h}$, NSC745887treated cells had shrunken morphologies and lower densities, which are certain markers of cell death. (C) Cell proliferation in the two GBM cell lines was determined using a common biomarker and Western blotting. Western blotting of the expression of Ki-67 suggested that NSC745887 decreased cell proliferation. Data are presented as the mean $\pm \mathrm{SD}$, with statistically significant values of \#\# $p<0.01$, \#\#\#p 0.001 compared to the control group. 
A
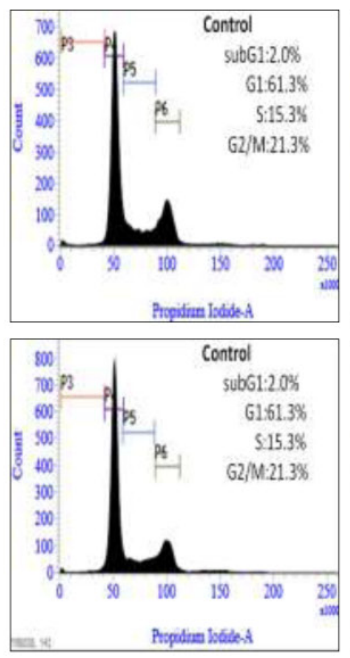

$\mathrm{C}$
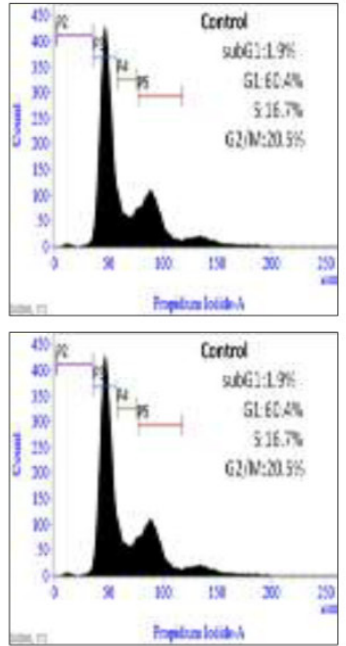

U118M
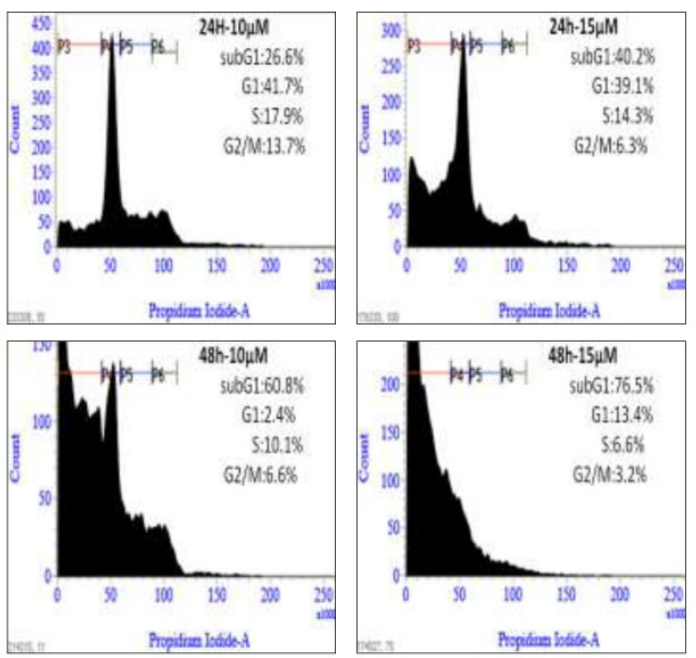

\section{U87M}
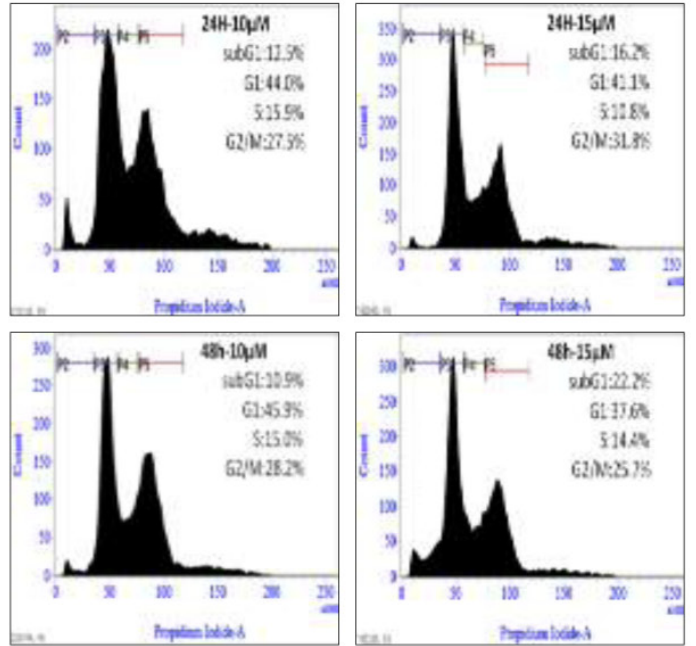

B

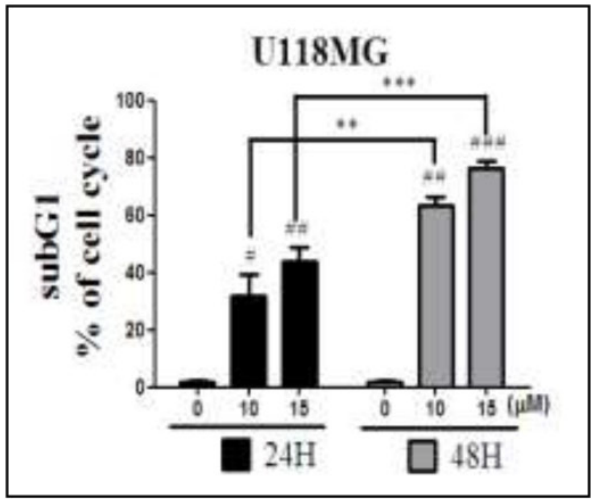

D

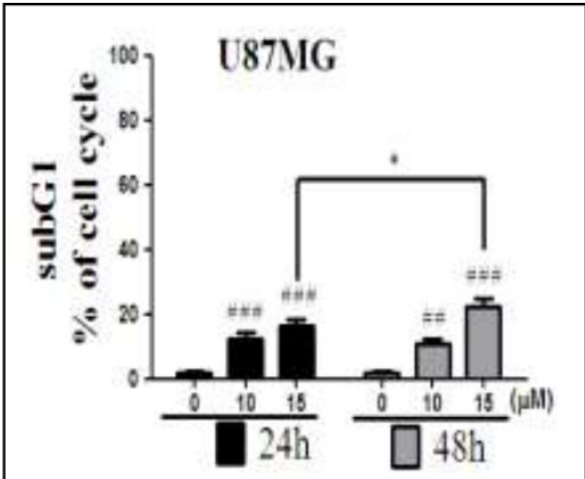

$\mathrm{E}$
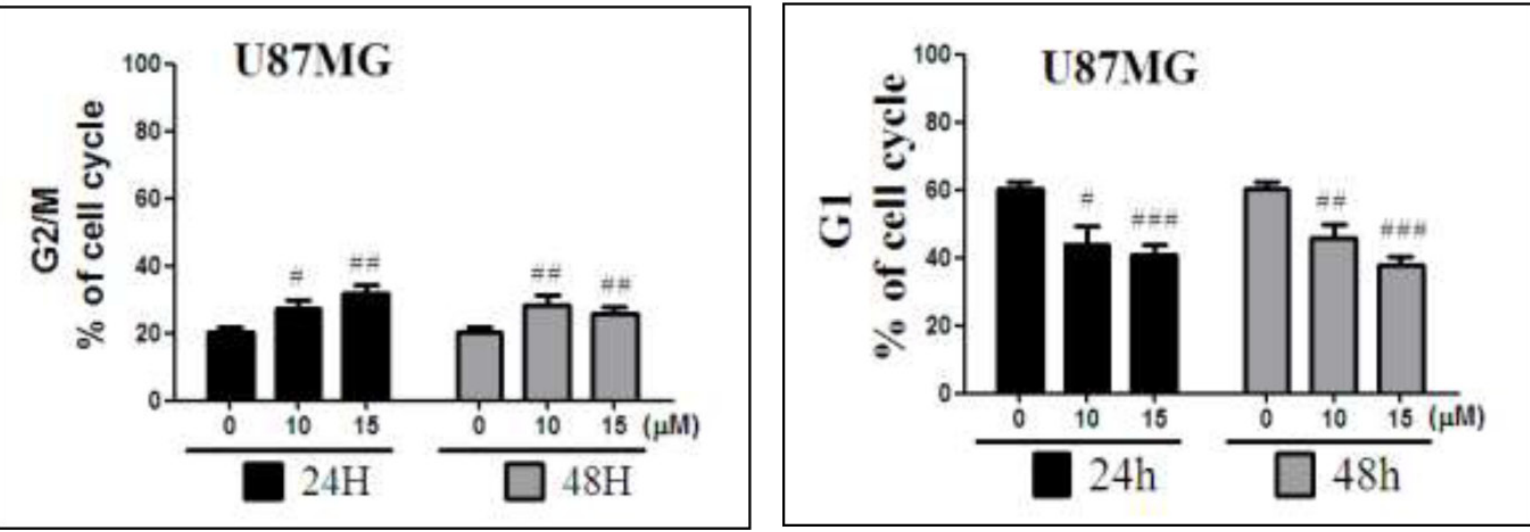

Figure 3: Regulation of the cell cycle by NSC745887 treatment of U118MG and U87MG cells. (A) Cell-cycle phase distributions were analyzed with increasing doses of NSC745887 $(10$ and $15 \mu \mathrm{M})$ for 24 and $48 \mathrm{~h}$, and representations of the cell-cycle modes of U118MG cells. (C) U87MG cells are shown. (B, D) Quantitative analyses of U118MG and U87MG cell populations in the sub- $\mathrm{G}_{1}$ phase using BD FACSuite analytical software. (E) Quantitative analyses of U87MG cell populations in the $\mathrm{G}_{2} / \mathrm{M}$ and $\mathrm{G}_{1}$ phases. Data are presented as the mean $\pm \mathrm{SD}$; statistical significance is indicated by ${ }^{\#} p<0.05,{ }^{\# \#} p<0.01,{ }^{\# \# \#} p<0.001$ compared to the control group. ${ }^{*} p<0.05,{ }^{* *} p<0.01,{ }^{* * *} p<0.001$, compared to the same concentration at 24 and $48 \mathrm{~h}$. 


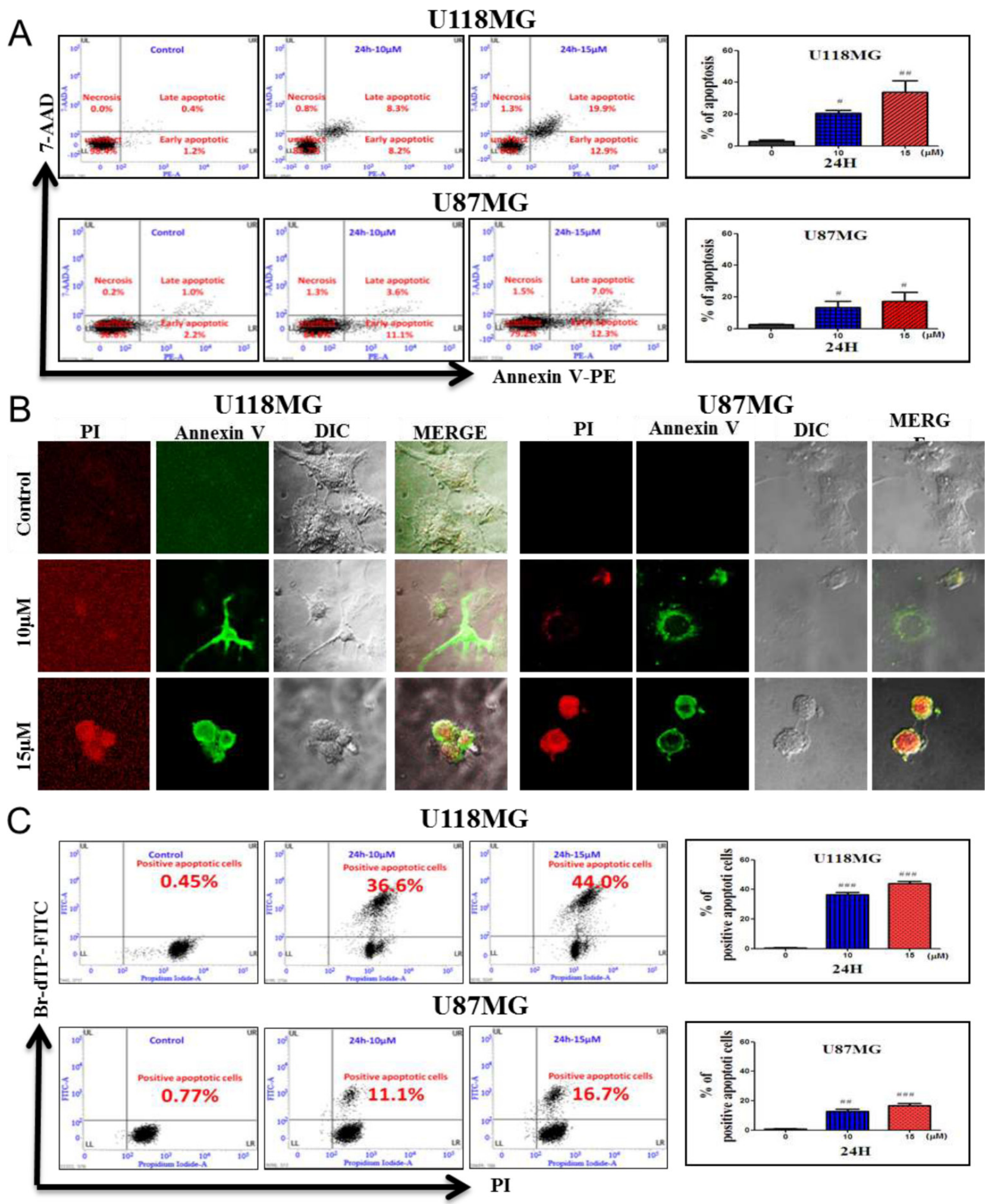

Figure 4: Induction of morphological and biochemical features of apoptosis in human glioblastoma cells. Treatments: control (CTL), and incubation with 10 and $15 \mu \mathrm{M}$ NSC745887 for 24 h. (A) Annexin V-PE/7-AAD double-staining and flow cytometric analysis of apoptotic populations after treatment. NSC745887 induced a significant population of cells in the A4 area, indicating induction of a biochemical feature of apoptotic death. (B) Confocal microscopic imaging to examine morphological features of apoptosis after cells were stained with Annexin V-FITC and propidium iodide. (C) Determination of the percentage of apoptosis based on morphological and biochemical features revealed by a TUNEL assay. A significant difference between the control (CTL) and treatment is indicated by ${ }^{*} p<0.05$ or $^{* *} p<0.01$. Results are representative of three independent experiments. 
chromatin [24], is a sensitive marker of detectable reactions to DSBs [25]. Therefore, we determined its effect on DNA damage in U118MG and U87MG cells at $24 \mathrm{~h}$ after NSC745887 treatment by a Western blot analysis (Figure 5, Supplementary Figure 5 in Supplementary Information). Expression of phosphorylated $\mathrm{H} 2 \mathrm{AX}(\gamma \mathrm{H} 2 \mathrm{AX})$ was detected in a majority of treated cells. As expected, these data indicated that NSC745887 triggered dose-dependent upregulation of $\mathrm{H} 2 \mathrm{AX}$ phosphorylation which was correlated with DNA damage. Cells with damaged DNA are hard to restore and may experience apoptosis and cellcycle arrest; they may also initiate DNA damage responses by a variety of protein kinases. H2AX containing a conserved SQ motif (S139 Q140) is recognized as the core target motif of serine/threonine kinases including ataxiatelangiectasia mutated (ATM) and RAD3-related (ATR), and initiate ATM and ATR phosphorylation following H2AX phosphorylation after DNA damage [24]. In the DNA damage signaling pathway, checkpoint kinase 1 (CHK1), CHK2, RAD51 [26], and p53 [27] are activated by ATM and ATR to regulate the cell cycle [28], initiate apoptosis [29], or repair DNA damage [30]. Thus, we also evaluated levels of phosphorylated and total protein DNA damage-response factors in NSC745887-treated U118MG and U87MG cells. As shown in Figure 5B and 5C, NSC745887 resulted in phosphorylation of ATM/ATR and CHK1/CHK2, while RAD51 expression was significantly suppressed and p53 was upregulated in U87MG cells. As we obtained significant DNA damage-response signaling in GBM cells with NSC745887 treatment, we also examined expressions of cell cycle-associated proteins, such as the phosphatase activity of cell division cyclin 25 (CDC25) which is inactivated by CHK1/CHK2 [31]. The CDC25c protein activates the cyclin $\mathrm{B} 1 / \mathrm{CDC} 2$ complex leading to $\mathrm{G}_{2} / \mathrm{M}$ phase arrest [32] as well as $\mathrm{CDC} 25 \mathrm{a}$ regulation at the $\mathrm{S}$ phase [33]. As shown in Figure 5D, NSC745887 resulted in suppression of $\mathrm{CDC} 25 \mathrm{c}$ and cyclin $\mathrm{B} 1$ as well as $\mathrm{CDC} 2$ phosphorylation in U87MG cells. In U118MG cells, we observed no cell cycle-associated protein changes under NSC745887 treatment. Overall, these results indicated that NSC745887 could induce DNA damage in GBM cells and activate the ATM/ATR and CHK1/CHK2 pathways; these effects may trigger the arrest of cell-cycle progression at the $\mathrm{G}_{2} / \mathrm{M}$ phase and promote apoptosis.

\section{NSC745887 engages intrinsic and extrinsic apoptotic pathways}

We next studied the action of the intrinsic apoptotic pathway through the DDR, which increases proapoptotic cysteinyl aspartic acid-protease-3 (caspase-3) and poly(ADP-ribose) polymerase (PARP) expressions and downregulates B-cell lymphoma protein 2 (Bcl2)associated $\mathrm{X}$ protein (Bax) heterodimer formation, through which Bax promotes cell death by competing with $\mathrm{Bcl} 2$ to adjust mitochondrial dynamics during the apoptotic process [27, 34]. Following mitochondrial membrane depolarization, initiation of the assembly of the apoptosome results in activation of the initiator, caspase- 9 , and the downstream effector, caspase- 3 , and ultimately cell death [35]. DcR3 expression is elevated in tumor cells and is also associated with autoimmune and inflammatory diseases [36]. However, further studies on the regulation of DcR3 expression in gliomas by NSC745887 are needed to understand this remarkable expression pattern. To study the mechanism of action, efforts were directed toward how DcR3 competes with Fas in binding to FasL and inhibits FasL-induced apoptosis, which involves extrinsic signaling pathways, initiating apoptosis through transmembrane receptor-mediated interactions, and targeting effecters such as caspase-8, $\mathrm{Bid}$, and Bcl2 [37]. Evaluation of the overexpression of DcR3 in GBM [38] led us to investigate its involvement in triggering apoptosis. U118MG and U87MG cells were treated with NSC 745887 for $24 \mathrm{~h}$ and analyzed by Western blotting. As shown in Figure 6A (Figure 6, Supplementary Figure 6 in Supplementary Information), the ratio of Bax-Bcl2 was significantly upregulated, and caspase- 3 and PARP were cleaved. DcR3 was also overexpressed in untreated cells and was downregulated in NSC745887treated cells, while the affecter proteins of caspase- 8 and caspase- 9 were activated by the cleaved form, increasing the Bid protein level (Figure 6B). We then assessed mitochondrial function following NSC745887 treatment by first characterizing the mitochondrial membrane potential (MMP) in U118MG and U87MG cells using JC-1 staining. As shown in Figure 6C, red fluorescence was seen in control cells, indicating the presence of JC-1 dye in the aggregated form and revealing the polarization potential of mitochondrial membranes. Although the mechanism is not fully understood, NSC745887-treated cells showed enhanced green fluorescence, indicating the presence of JC-1 monomers and a depolarized MMP. JC-1 staining was further verified to be due to mitochondrial membrane depolarization using a quantitative flow cytometric analysis. It showed reduced JC-1 aggregates and amplified JC-1 monomers in NSC745887-treated cells compared to untreated cells (Figure 6D). Our results suggest the involvement of caspase- $8,-9$, and -3 activation and PARP division in cell death through intrinsic and extrinsic apoptotic pathways.

\section{$\left[{ }^{18} \mathrm{~F}\right]-\mathrm{PET}$ in an experimental animal model}

$\left[{ }^{18} \mathrm{~F}\right]$-PET is used in the clinic for staging a range of cancers and has been widely used to investigate cancers $[39,40]$. The glucose analogue, $2-\left[{ }^{18} \mathrm{~F}\right]-\mathrm{FDG}$, is one of the most commonly used PET radiotracers. While clinical PET imaging has significantly expanded over the past decade, $\left[{ }^{18} \mathrm{~F}\right]-$ FDG PET imaging is still very commonly used and is widely available. To further evaluate the efficiency of NSC745887 for treating 


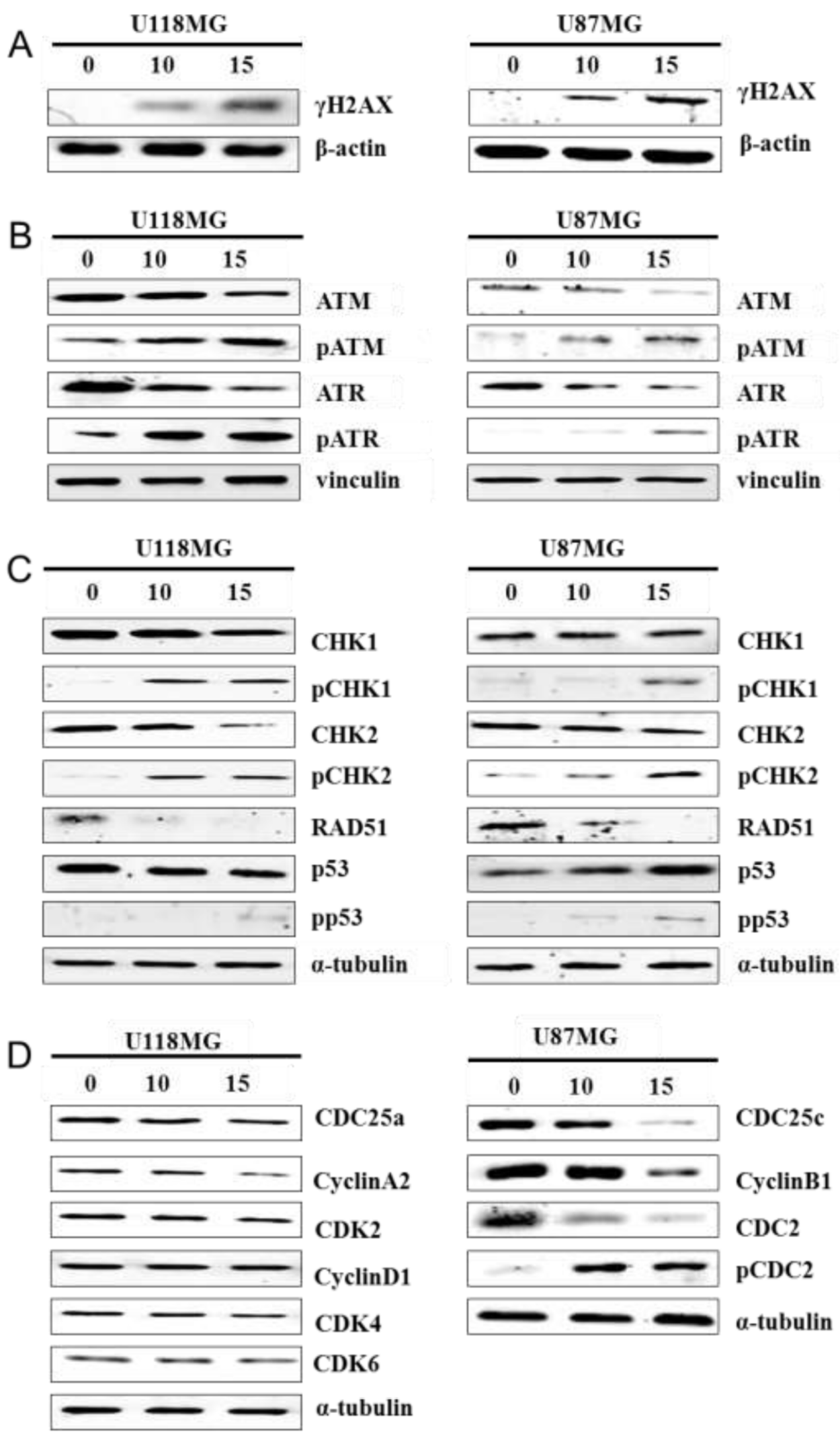

Figure 5: NSC745887 activates ATM and ATR signaling. Protein expression levels of (A) $\gamma \mathrm{H} 2 \mathrm{AX}$; (B) ATM, phosphorylated (p)-ATM, ATR, p-ATR, (C) CHK1, p-CHK1, CHK2, p-CHK2, RAD51, p53, p-p53 (D) CDC25a, cyclin A2, CDK2, cyclin D1, CDK4/6, $\mathrm{CDC} 25 \mathrm{c}$, cyclin B1, CDC2, and p-CDC2 were detected in cells treated with or without NSC745887 (10 or $15 \mu \mathrm{M})$ for $24 \mathrm{~h}$ using Western blotting. $\beta$-Actin, vinculin, and $\alpha$-tubulin were used as loading controls. Data are presented as the mean $\pm \mathrm{SD}$; statistical significance is indicated by ${ }^{\#} p<0.05,{ }^{\#} p<0.01,{ }^{\# \#} p<0.001$ compared to the control. 

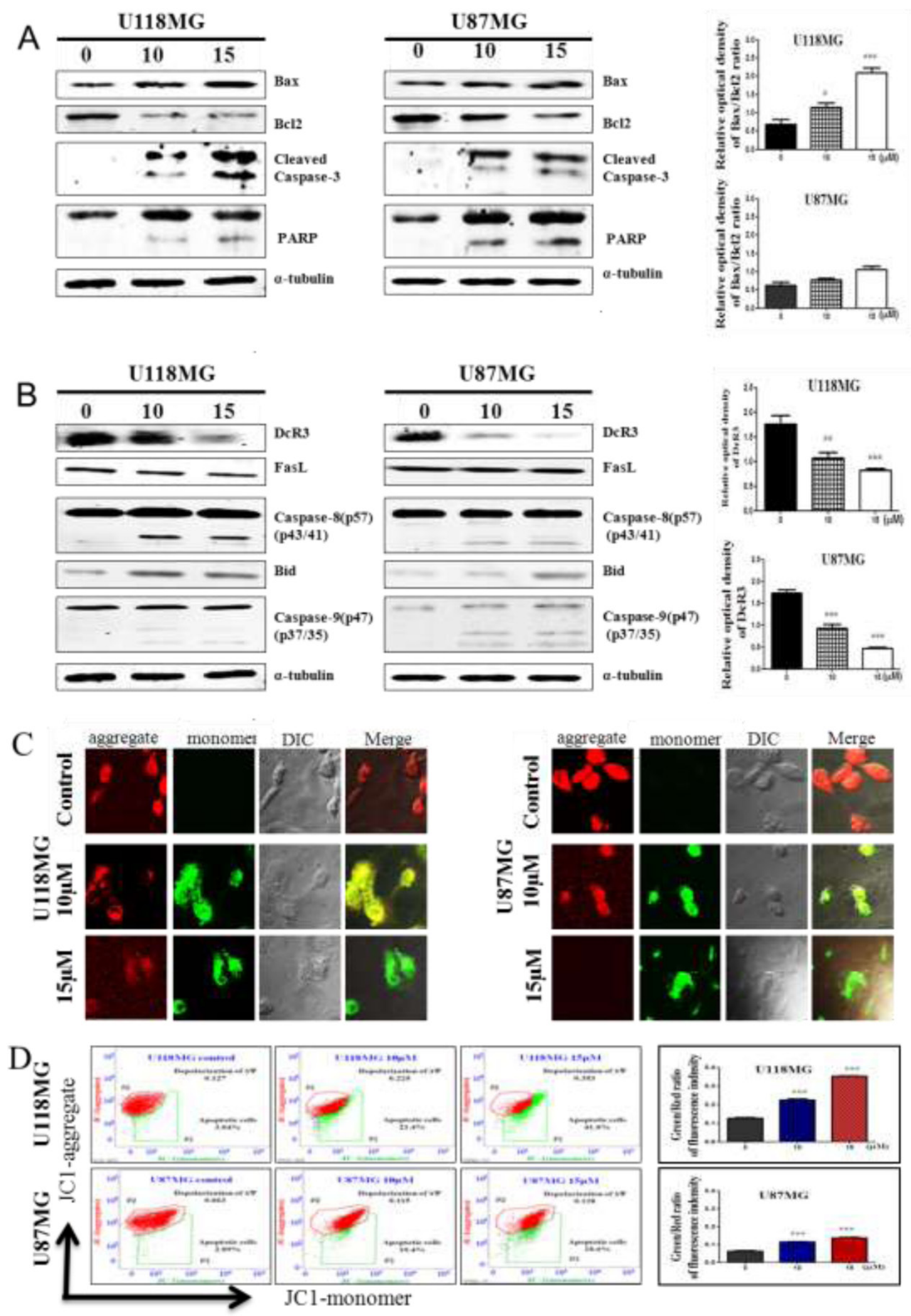

Figure 6: NSC745887 treatment induces the intrinsic and extrinsic apoptotic pathways in GBM cell lines. Protein expression levels of (A) Bax, Bcl2, cleaved caspase-3, and poly(ADP ribose) polymerase (PARP); (B) DcR3, FasL, cleaved caspase-8, Bid, and cleaved caspase-9 were detected in cells treated with or without NSC745887 (10 or $15 \mu \mathrm{M})$ for $24 \mathrm{~h}$ by Western blotting. $\alpha$-Tubulin was used as a loading control. (C) Fluorescence staining of JC-1, which shows the mitochondrial membrane potential change, was analyzed by confocal microscopy to show the cell morphology and then $(\mathbf{D})$ was detected by a flow cytometric analysis. Data are presented as the mean $\pm \mathrm{SD}$; statistical significance is indicated by ${ }^{\#} p<0.05,{ }^{\#} p<0.01,{ }^{\# \#} p<0.001$ compared to the control. 
GBM in vivo, we subcutaneously injected BALB/c nude xenograft mice with $10^{6} \mathrm{U} 118 \mathrm{MG}$ cells. Mice were treated with NSC745887 (5 mg/kg) or DMSO (control group) via an i.p. injection every day. Animal-PET scan resolution of the tumor progress showed significant differences between the control and treatment groups (Figure 7A, Supplementary Figure 7 in Supplementary Information). The mean specific uptake value of $\left[{ }^{18} \mathrm{~F}\right]-$ FDG in the NSC745887 group $(0.139 \pm 0.02, n=6)$ was consistent with that of the DMSO group $(0.136 \pm 0.0$, $n=6)(p>0.05)$ on day 0, while that of the NSC745887 group was significantly lower than that of the DMSO group on day $28(0.097 \pm 0.02$ vs. $0.138 \pm 0.01$, respectively, $p<0.01$ ) (Figure 7B). The tumor volume of the NSC745887 group $\left(61.15 \pm 6.89 \mathrm{~mm}^{3}\right)$ was consistent with that of the DMSO group $\left(64.01 \pm 14.08 \mathrm{~mm}^{3}\right)(p>0.05)$ on day 0 , while that of the NSC745887 group was significantly smaller than that of the DMSO group on day 28 (44 \pm 12 vs. $496 \pm 480 \mathrm{~mm}^{3}$, respectively, $p<0.05$ ) (Figure 7C). Mice were euthanized at the endpoint of the experiment (on day 29), and tumor sizes were measured (Figure 7D). The tumor weight of the NSC745887 group $(210 \pm 103$ $\mathrm{mg}$ ) was significantly smaller compared to the DMSO group $(548 \pm 554 \mathrm{mg})(p<0.01)$. An IHC analysis of tumor tissues showed that the Ki-67 level was downregulated, and $\gamma \mathrm{H} 2 \mathrm{AX}$ and cleaved caspase- 3 levels were upregulated in NSC745887-treated mice (Figure 7E). To explore the toxicity of NSC745887, we monitored body weights of the mice. Body weights of mice in neither group greatly changed during the experiment. On day 0 , the weight was $19.5 \pm 0.9 \mathrm{mg}$ in the treatment group and $19.01 \pm 0.7 \mathrm{mg}$ in the DMSO group, $(p>0.05)$, and on day 28 , they were $18.7 \pm 1.5$ and $19.9 \pm 0.8 \mathrm{mg}$, respectively, $(p>0.05)$ (Figure 7F). No damage was found in tissues of the heart, kidneys, or liver during the histopathological analysis of either group (Figure 7G). This toxicity evaluation showed that NSC745887 had no toxic effects on either group as assessed by the body weight and vital organ function in mice, which suggests that NSC745887 is safe. In conclusion, our in vitro studies provide a basis for screening tests to select suitable cell lines for the development of human tumor xenograft models for animal-PET imaging.

\section{DISCUSSION}

In this study, we established a molecular basis for the efficacy of a novel small molecule and its selective and tumor-suppressive effects on human glioblastoma cells (p53 wild-type and mutated-type) in vitro and in vivo. Several discrete mechanisms of anticancer activity were proposed for NSC745887 herein, including NSC745887 induction of DNA damage and apoptosis. In addition, NSC745887 induced DNMT3a gene expression in HeLa cells [8]. On the other hand, the effect of NSC745887 on protein stability, including $\mathrm{p} 53$, might compensate for the low affinity of topoisomerase IIA, as demonstrated by our previous docking mode analysis [8]. NSC745887 was designed following intensive research on the biology of G-quadruplex stabilizers [9]. The design rationale comprised certain structural features shared by known quadruplex-binding small molecules, with particular emphasis on an electron-rich aromatic surface, the potential for a flat conformation, and the ability to participate in hydrogen bonding [8, 41]. We further found that NSC745887 is readily accessible in only one synthesis step that is easily scalable and amenable to molecular diversity [9]. To complement the chemically induced synthetic lethality, small-molecule inhibitors of DNA repair pathways are being intensively investigated as chemotherapeutic strategies [42, 43]. This approach analyzes DNA fragmentation, cell-cycle arrest, MMP changes and apoptosis-mediated signaling pathways and provides an opportunity to identify novel small molecules in the DDR through follow-up target identification studies. We also examined the uptake kinetics of NSC745887 in both p53 wild-type and p53-mutant GBM cell lines. These data will guide the selection of tumor types for animal studies and translational development, which are ongoing in our laboratories.

A previously established cytotoxic anticancer drug achieved its efficacy via promoting the formation of DNA DSBs and DDRs [44]. Among the many different DNA lesions, DNA DSBs are the most deleterious and are part of the cellular DDR network [45]. Our drug design strategy was to exclude false positives and select compounds with the potential for targeting DDR pathways. Based on this design, NSC745887 was synthesized and shown to promote apoptosis in GBM cells in dose- and timedependent manners. Dissociation of the complex formed was analyzed by flow cytometry, and cell-cycle arrest was evaluated in the presence of increasing amounts of the small molecule. Small-molecule inhibitors induced DNA damage and protein expressions of $\mathrm{Ki}-67$ and $\gamma \mathrm{H} 2 \mathrm{AX}$, and cleaved caspase- 3 by inducing cell-cycle arrest. Activation of the DDR machinery, which if it does not repair RAD51driven homologous recombination (HR), will trigger cellcycle arrest, senescence, and apoptosis [46]. For example, breast cancer cells carrying mutations of the BRCA2 gene are deficient in the HR repair pathway and are consequently particularly sensitive to chemical inhibitors of alternative DNA repair pathways [47].

DNA DSBs are among the most toxic DNA lesions and can be generated by cancer chemotherapy [48]. Cellular responses to DNA damage upon DSB induction include activation of two protein kinase signaling pathways, ATMCHK2 and ATR-CHK1 [49]. This process, is accompanied by p53-deficient cell progression through the $\mathrm{S}$ phase and is arrested by a DNA damage checkpoint in the $\mathrm{G}_{2}$ phase [50]. Interestingly, phosphorylation and activation of p53 following activation of the ATM/ATR induces $\mathrm{G}_{2} / \mathrm{M}$ 


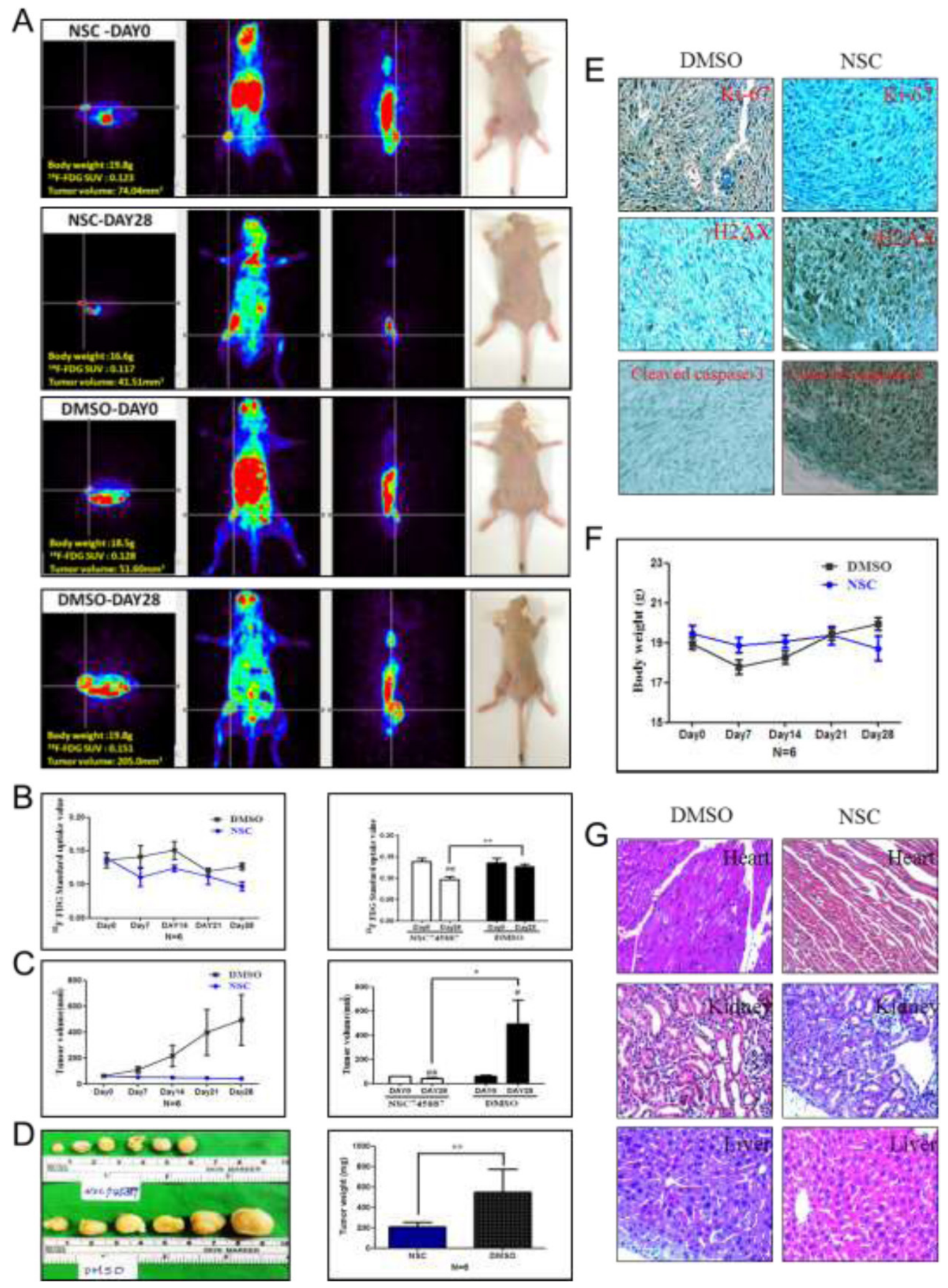

Figure 7: NSC745887 promotes growth inhibition in xenografts. In vivo PET imaging data were analyzed in a NSC745887treated group and a DMSO group using an animal-PET system. (A) $\left[{ }^{18} \mathrm{~F}\right]$-FDG PET images from 15 to 35 min in U118MG expressing xenograft-bearing mice after intraperitoneal administration of radiotracers. (B) Quantitative analyses of specific $\left[{ }^{18} \mathrm{~F}\right]$-FDG uptake values and (C) tumor volumes. (D) The tumor weight was measured at the endpoint. (E) Representative images of IHC staining of xenograft tumors. Protein levels of Ki-67, $\gamma \mathrm{H} 2 \mathrm{AX}$, and cleaved caspase-3. (F) Body weights were measured during treatment. (G) Representative image of $\mathrm{H} \& \mathrm{E}$ staining of the heart, liver, and kidneys in xenograft mice. ${ }^{*} p<0.05,{ }^{* *} p<0.01$ comparing days 0 and 28 . ${ }^{*} p<0.05$, ${ }^{\#} p<0.01$ comparing the NSC745887 and DMSO groups. 
arrest; specifically, p53 restrains $\mathrm{CDC} 25 \mathrm{c}$, a phosphatase that promotes mitosis, mainly by blocking activity of the cyclin B1/CDC2 complex [51, 52]. Upregulation of Bax protein levels results in formation of a heterodimer with an oncogene-derived protein (Bcl-2), thus increasing the opening of the mitochondrial voltage-dependent anion channel, which leads to loss of the membrane potential, induced by $\mathrm{p} 53$, which is further evidence of p53-mediated apoptosis [53, 54]. To identify the mechanisms, we sought out potential targets of this process in these cells. Our finding that $\mathrm{CDC} 25 \mathrm{c}$ and cyclin $\mathrm{B} 1 / \mathrm{CDC} 2$ were decreased in NSC745887-treated cells is in agreement with earlier results, in which DNA repair or cell-cycle arrest and apoptosis are responses after DNA damage. In contrast, our finding that $\mathrm{CDC} 25 \mathrm{a}$, cyclin $\mathrm{A} 2 / \mathrm{CDK} 2$, and cyclin D1/CDK4/6 remained at functional levels after NSC745887 treatment demonstrates progression in the transition to the $\mathrm{G}_{1}-\mathrm{S}$ phase. Furthermore, Fas is a homotrimeric type II transmembrane protein present on cytotoxic T lymphocytes. It acts via trimerization of Fas receptors, which cross the membrane of the objective cell, and are essential for downstream events that disseminate the apoptotic signal [55]. DcR3 can be defined as an immunomodulator which is reported to interact with the FasL and is overexpressed in some malignant tumors [56]. Most importantly, the apoptotic effect of FasL/Fas signaling is obstructed by DcR3, a distinct secreted member of the tumor necrosis factor receptor superfamily that functions to prevent FasL/Fas interactions by competitively binding to the membrane-bound Fas and rendering them inactive by native glycosylation, which results in a reduced tendency to couple [56-58]. These data provided solid evidence that Fas forms a death-inducing signaling complex (DISC) upon ligand binding. This causes complete apoptosis and subsequent caspase- 8 activation, which catalyzes the cleavage of the proapoptotic $\mathrm{BH} 3$-only protein, $\mathrm{Bid}$, and discourages the Bcl-2 family from allowing Bax to be translocated to the outer mitochondrial membrane, thus permeabilizing it and facilitating release of proapoptotic proteins such as cytochrome c. These eventually lead to DNA degradation, membrane blebbing, and other hallmarks of apoptosis [59]. These data challenged the idea that DcR3 is extremely elevated in most patients with GBM and contributes to tumor cell evasion of host immune surveillance [38]. We found that DcR3 is expressed in untreated U118MG and U87MG cells, and was suppressed after NSC745887 treatment based on unchanged FasL levels. To our knowledge, this is the first direct comparison of a DcR3-expressing ensemble and mechanism of action of a small molecule to incorporate protein flexibility in structure-based drug design. Subsequently, these data argued in favor of activated caspase- 8 promoting $\mathrm{Bid}$ upregulation and increasing the $\mathrm{Bax} / \mathrm{Bcl} 2$ ratio, thus resulting in mitochondrial membrane depolarization, which is in agreement with FasL/Fas signaling. The data presented above conclusively point to the involvement of DDRs and apoptosis as important pathways to remediate DNA damage induced by NSC745887, so that it either directly alters DNA sequences or causes mutations. Further studies will examine our novel small-molecule inhibitor to delineate the structural requirements to further optimize its structure and control its polypharmacology.

\section{MATERIALS AND METHODS}

\section{Cell lines, reagents, and test compounds}

The synthesis of NSC745887 was described in our earlier study [9]. Chemicals used in this study were mostly purchased from Sigma-Aldrich (St. Louis, MO, USA). The human U87MG glioblastoma cell line was purchased from the Bioresource Collection Research Center (Taipei, Taiwan). U118MG cells were obtained from Dr. Dueng-Yuan Hueng (National Defense Medical Center, NDMC, Taipei, Taiwan). U118MG and U87MG cells were maintained in Dulbecco's modified Eagle's medium (DMEM) supplemented with 10\% fetal bovine serum (FBS), 1\% penicillin, and 1\% streptomycin (Gibco/BRL, Grand Island, NY, USA). The medium was replaced with fresh complete medium $24 \mathrm{~h}$ before further experiments. All cell lines were maintained in a fully humidified incubator containing $5 \% \mathrm{CO}_{2}$ at $37^{\circ} \mathrm{C}$. The media and FBS were purchased from Mediatech (Atlanta Biologicals, Atlanta, GA, USA).

\section{Assay protocol}

Cell viability was evaluated using a 3-(4,5-dime thylthiazol-2-yl)-2,5diphenyltetrazoliumbromide (MTT; Sigma, St. Louis, MO, USA) assay. Cells $\left(4 \times 10^{4}\right)$ were calculated with a cell counter (Bio-Rad Laboratories, Hercules, CA, USA) plated in 24-well plates and incubated at $37^{\circ} \mathrm{C}$ for $24 \mathrm{~h}$. Later, cells were grown with or without different concentrations of NSC745887, and cells were cultured to the indicated time points. Following this, cells in each well were treated with $500 \mu \mathrm{L}$ of an MTT solution $(5 \mathrm{mg} / \mathrm{mL}$ in phosphate-buffered saline (PBS)) and incubated for $4 \mathrm{~h}$. Formazan crystals were solubilized in $500 \mu \mathrm{L}$ DMSO, and optical densities were detected at a wavelength of $570 \mathrm{~nm}$ by a Synergy HT multi-detection microplate reader (Awareness Technology, Palm City, FL, USA). The relative survival rate was normalized to the untreated group and summarized for five independent experiments.

\section{Western blot analysis}

After various treatments, glioma cells were lysed in ice-cold RIPA buffer $(25 \mathrm{mM}$ Tris- $\mathrm{HCl}$ at $\mathrm{pH} 7.6,150 \mathrm{mM}$ $\mathrm{NaCl}, 1.0 \%$ TritonX-100, 1.0\% sodium deoxycholate, and $1 \%$ sodium dodecylsulfate (SDS)) containing protease and phosphatase inhibitors (GeneTex). Protein samples (100 $\mu \mathrm{g}$ 
per lane) were electrophoresed on $5 \%$ (for $>300 \mathrm{kDa}$ ), $10 \%$ (for $40 \sim 300 \mathrm{kDa}$ ), or $12 \%$ SDS polyacrylamide gels (for $<40 \mathrm{kDa}$ ) and transferred to a $0.45-\mu \mathrm{M}$ filter pore size hydrophobic Immobilon-P polyvinylidene fluoride (PVDF) membrane (Millipore). Strips from the membrane were blocked with blocking buffer (Genestar) at room temperature for $5 \mathrm{~min}$ and incubated overnight at $4^{\circ} \mathrm{C}$ with a 1:1000 dilution of rabbit antibodies against Ki-67, $\gamma \mathrm{H} 2 \mathrm{AX}$, ATM, phosphorylated (p)-ATM, ATR, p-ATR, CHK1, p-CHK1, CHK2, p-CHK2, RAD51, p53, p-p53, CDC25a, CDC25c, cyclin A2, cyclin B1, cyclin D1, CDK2, CDK4, CDK6, CDC2, p-CDC2, Bc12, Bax, DcR3, FasL, Bid, PARP, cleaved caspase-3, cleaved caspase-8, cleaved caspase-9, vinculin, $\beta$-actin, and $\alpha$-tubulin. After washing, strips were incubated with a $1: 10^{4}$ dilution of infrared (IR) dye-conjugated anti-rabbit immunoglobulin G (IgG) antibodies (LI-COR, Bioscience) in a dark room for $1 \mathrm{~h}$. Then, the fluorescence density of the bands on the PVDF membrane was quantified by densitometry using Odyssey ${ }^{\circledR}$ CLx Infrared Imaging System (LI-COR), taking the density of the control sample as $100 \%$ and expressing the density of the test sample relative to the expression of the internal control as a relative value.

\section{Flow cytometry-based apoptosis detection}

A flow cytometric analysis was utilized to measure cell-cycle dynamics in different cell phases. In total, $2 \times 10^{5}$ cells/well were seeded in six-well plates and incubated for $24 \mathrm{~h}$. After application of NSC745887 for 24 or $48 \mathrm{~h}$, cells were digested with $0.05 \%$ trypsin and gathered, and the prepared cell suspension was fixed with $75 \%$ ethanol at $-20^{\circ} \mathrm{C}$ overnight. The cell suspension was washed with PBS and stained with $500 \mu \mathrm{L}$ propidium iodide (PI)/RNase staining solution (BD Biosciences, Franklin Lakes, NJ, USA) for $15 \mathrm{~min}$ at room temperature in the dark. In total, $10^{4}$ stained cells were analyzed using the FACSVerse ${ }^{\mathrm{TM}}$ laser flow cytometric analysis system (BD Biosciences) for each sample. At least four independent experiments were conducted. Apoptosis assays were prepared by seeding $2 \times 10^{5} \mathrm{U} 118 \mathrm{MG}$ or U87MG cells in six-well plates overnight, and growth medium either with or without different concentrations of NSC745887 was added for 24 or 48 h. An Annexin V-PE Dead Cell Apoptosis kit (BD Biosciences) was utilized for the apoptotic cell death analysis following the manufacturer's protocol to prepare samples. Cells were trypsinized and washed twice with PBS, and pellets were resuspended in $100 \mu \mathrm{L}$ of binding buffer, $5 \mu \mathrm{L}$ Annexin V-PE, and $10 \mu \mathrm{L}$ 7-AAD, mixed, and incubated for $15 \mathrm{~min}$ in the dark at room temperature. Next, $400 \mu \mathrm{L}$ of binding buffer was added to cells, and $10^{4}$ events were acquired for each sample. 7-AAD was analyzed in a flow cytometer (FACSVerse ${ }^{\mathrm{TM}}$; BD Biosciences) at $488 \mathrm{~nm}$, and Annexin V-PE fluorescence was detected at $617 \mathrm{~nm}$. An APO-DIRECTTM Kit (BD Biosciences) was utilized for the DNA damage analysis, and a Flow
Cytometry Mitochondrial Membrane Potential Detection Kit (BD Biosciences) was used to detect a normal $\Delta \psi$ in healthy mitochondria or a decreased $\Delta \psi$ in mitochondria of apoptotic cells. Each experiment was conducted at least three times. Following acquisition, data were analyzed using Flow Jo vers. 7.6.5 software (Tree Star, Ashland, OR, USA). In total, $10^{4}$ cells were analyzed for each sample.

\section{Mouse xenograft model and positron emission tomographic (PET) scan analysis}

All protocols were authorized by the Institutional Animal Care and Use Committee of the NDMC (approval no.: IACUC16-075, Taipei, Taiwan). Female BALB/ cAnN.Cg-Foxn1nu/CrlNarl mice (8 weeks old; 20 22 g) were acquired from the National Laboratory Animal Center (Taipei, Taiwan) and were free from contamination as confirmed by health reports. Following anesthetization with isoflurane, $10^{6} \mathrm{U} 118 \mathrm{MG}$ cells were subcutaneously inoculated, and tumors grew up to $50 \mathrm{~mm}^{3}$. Mice bearing gliomas were treated with $5 \mathrm{mg} / \mathrm{kg} /$ day NSC745887 via an intraperitoneal (i.p.) injection, and an equal amount of DMSO was administered to the control group. To evaluate the NSC745887 treatment effect on tumors, BALB/c nude mice were monitored using $\left[{ }^{18} \mathrm{~F}\right]$-2-deoxy-2-fluoro-D-glucose ( $\left[{ }^{18} \mathrm{~F}\right]$-FDG)/animal-PET) scanning on days $0,7,14,21$, and 28 after treatment. The complete imaging procedure was carried out in the Laboratory Animal Center of the NDMC, which is certified by the Association for Assessment and Accreditation of Laboratory Animal Care International (AAALAC 2007). BALB/c nude mice of both groups $(n=6)$ were i.p.-injected with $285 \sim 295 \mu \mathrm{Ci}(9.5 \sim 10.5 \mathrm{MBq})$ of $\left[{ }^{18} \mathrm{~F}\right]$-FDG after overnight starvation. After allowing the $\left[{ }^{18} \mathrm{~F}\right]$-FDG injection to be distributed for $15 \mathrm{~min}$, mice were anesthetized, and were imaged for 20 min using animal-PET statistical scanning with BIOPET105 (Bioscan, Washington DC, USA) with the energy window set to $250 \sim 700 \mathrm{keV}$. Three-dimensional (3D)-ordered subset expectation maximization (OSEM) was used for image reconstruction and AMIDE software (vers. 1.0.4) for image data analysis. The tumor volume was quantitated by estimating the standard uptake value (SUV) of $\left[{ }^{18} \mathrm{~F}\right]-\mathrm{FDG}$, which indicates the level of $\left[{ }^{18} \mathrm{~F}\right]-\mathrm{FDG}$ in a volume of interest (VOI) (representative of a focal tumor) relative to average $\left[{ }^{18} \mathrm{~F}\right]$-FDG levels in the whole body. The experiment lasted 28 days; then, all of the mice were euthanized and fixed in 4\% paraformaldehyde on day 29. Tumor tissues were collected and weighed, and vital organs including the heart, kidneys, and liver were extracted for hematoxylin and eosin (H\&E) and immunohistochemical (IHC) staining.

\section{Histological and IHC evaluations}

Xenograft tumors and vital organs were fixed in $4 \%$ paraformaldehyde at $4{ }^{\circ} \mathrm{C}$ for $48 \mathrm{~h}$. Tissues were embedded in a standard tissue-freezing medium (O.C.T. 
compound) and sliced into 4- $\mu$ m-thick sections. Standard H\&E staining was carried out for a histomorphological evaluation of the heart, kidneys, and liver. Expressions of Ki-67 (\#9027, Cell Signaling), rH2AX (\#9718, Cell Signaling), and cleaved caspase-3 (\#9661, Cell Signaling) in tumors of the mice were detected with an IHC analysis, and were observed in 10 random fields for each group.

\section{Data analysis}

All experiments were performed at least three times, and values are reported as the mean \pm standard deviation (SD). Differences between groups were evaluated using the Kruskal-Wallis test followed by post-hoc comparisons with GraphPad Prime 5.0 software. Details of each statistical analysis used are recorded in the figure legends. Statistical significance was set to $p<0.05$.

\section{CONCLUSIONS}

We provide preclinical evidence for NSC745887, with a tetraheterocyclic motif, as a potential new agent for treating GBM. We showed that NSC745887 treatment induced DDR in GBM cells. This is consistent with an earlier model of p53 in regulating DNA damage caused by NSC745887, which invoked participation of a tetraheterocyclic system in its DNA-damaging effects and exhibited DNA fragmentation, cell cycle arrest, MMP changes, and an apoptosis-mediated signaling pathway. Our data are consistent with findings of the role of DcR3 in glioma progression [5]; it was reported to protect malignant gliomas from their functional and might be an interesting small molecule for DcR3 in drug design. This finding provides an explanation of the anticancer activity of NSC745887, which was hitherto unknown. We envision that the data presented herein can lay the foundation for evaluating NSC745887 as a novel anti-glioblastoma agent. To this end, the assays we report are likely to enable the discovery of novel anti-glioblastoma agents and will help advance the translational development of new biological targets in these clinically important pathways.

\section{Abbreviations}

Animal-PET: animal positron emission tomography; ATM: ataxia-telangiectasia mutated; ATR: ATM and Rad3-related; BCNU: carmustine; CCNU: lomustine, DcR3: decoy receptor 3; DDR: DNA damage response; DMEM: Dulbecco's modified Eagle's medium; DMSO: dimethyl sulfoxide; FasL: fatty acid synthetase ligand; FBS: fetal bovine serum; $\left[{ }^{18} \mathrm{~F}\right]-\mathrm{FDG},\left[{ }^{18} \mathrm{~F}\right]$ fluorodeoxyglucose; GBM: glioblastoma multiforme; IgG: immunoglobulin G; IHC: immunohistochemical; i.p, intraperitoneal; IR: infrared; MTT, 3-(4,5-dimethylthiazol2-yl)-2,5 diphenyltetrazoliumbromide; NCI: National Cancer Institute; OSEM: ordered-subset expectation maximization; PARP: poly(ADP-ribose) polymerase; PBS: phosphate-buffered saline; PI: propidium iodide; PVDF: polyvinylidene difluoride; SDS: sodium dodecylsulfate; TEA: trimethylamine; THF: tetrahydrofuran; TMZ, temozolomide.

\section{Author contributions}

Li-Yun Fann established the biological assay system and conducted the analyses; Tsung-Chih Chen, JiannFong Lee, and Ahmed Atef Ahmed Ali synthesized and characterized the compounds used in this study; Ying Chen, Da-Chen Chu, Shao-Ju Weng, Heng-Cheng Chu, Alexander T. H. Wu, Hsu-Shan Huang, and Kuo-Hsing Ma designed the research, analyzed results, and wrote the manuscript. *These authors contributed equally to this work.

\section{ACKNOWLEDGMENTS AND FUNDING}

We are grateful to Mr. Ta-Kai Chou for his technical assistance (PET Center, Department of Nuclear Medicine, Tri-Service General Hospital, National Defense Medical Center, Taipei, Taiwan). This study was supported by Taipei City Hospital grants B-0100-B-B18-22 and 10050-B-010051B1-286-B16023-6-0-0. The present study was supported by the Ministry of Science and Technology (MOST 1062113-M-038-003, 106-2314-B-016-011-MY3) and Taipei Medical University (TMUTOP103003-1, TMU105AE1-B29, and A-106-001).

\section{CONFLICTS OF INTEREST}

The authors disclose no potential conflicts of interest.

\section{REFERENCES}

1. Louis DN, Ohgaki H, Wiestler OD, Cavenee WK, Burger PC, Jouvet A, Scheithauer BW, Kleihues P. The 2007 WHO classification of tumours of the central nervous system. Acta Neuropathol. 2007; 114:97-109.

2. Omuro AM, Faivre S, Raymond E. Lessons learned in the development of targeted therapy for malignant gliomas. Mol Cancer Ther. 2007; 6:1909-1919.

3. Pitti RM, Marsters SA, Lawrence DA, Roy M, Kischkel FC, Dowd P, Huang A, Donahue CJ, Sherwood SW, Baldwin DT, Godowski PJ, Wood WI, Gurney AL, et al. Genomic amplification of a decoy receptor for Fas ligand in lung and colon cancer. Nature. 1998; 396:699-703.

4. Bai C, Connolly B, Metzker ML, Hilliard CA, Liu X, Sandig V, Soderman A, Galloway SM, Liu Q, Austin CP, Caskey CT. Overexpression of M68/DcR3 in human gastrointestinal tract tumors independent of gene amplification and its 
location in a four-gene cluster. Proc Natl Acad Sci U S A. 2000; 97:1230-1235.

5. Roth W, Isenmann S, Nakamura M, Platten M, Wick W, Kleihues P, Bahr M, Ohgaki H, Ashkenazi A, Weller M. Soluble decoy receptor 3 is expressed by malignant gliomas and suppresses CD95 ligand-induced apoptosis and chemotaxis. Cancer Res. 2001; 61:2759-2765.

6. Jiang P, Mukthavaram R, Chao Y, Bharati IS, Fogal V, Pastorino S, Cong X, Nomura N, Gallagher M, Abbasi T, Vali S, Pingle SC, Makale M, et al. Novel anti-glioblastoma agents and therapeutic combinations identified from a collection of FDA approved drugs. J Transl Med. 2014; 12:13.

7. Liu Z, Wang F, Zhou ZW, Xia HC, Wang XY, Yang YX, He ZX, Sun T, Zhou SF. Alisertib induces G2/M arrest, apoptosis, and autophagy via PI3K/Akt/mTOR- and p38 MAPK-mediated pathways in human glioblastoma cells. Am J Transl Res. 2017; 9:845-873.

8. Chang YL, Lee HJ, Liu ST, Lin YS, Chen TC, Hsieh TY, Huang HS, Huang SM. Different roles of p53 in the regulation of DNA damage caused by 1,2-heteroannelated anthraquinones and doxorubicin. Int J Biochem Cell Biol. 2011; 43:1720-1728.

9. Huang HS, Chen TC, Chen RH, Huang KF, Huang FC, Jhan JR, Chen CL, Lee CC, Lo Y, Lin JJ. Synthesis, cytotoxicity and human telomerase inhibition activities of a series of 1,2-heteroannelated anthraquinones and anthra[1,2-d] imidazole-6,11-dione homologues. Bioorg Med Chem. 2009; 17:7418-7428.

10. Lee YR, Chen TC, Lee CC, Chen CL, Ahmed Ali AA, Tikhomirov A, Guh JH, Yu DS, Huang HS. Ring fusion strategy for synthesis and lead optimization of sulfur-substituted anthra[1,2-c][1,2,5]thiadiazole-6,11-dione derivatives as promising scaffold of antitumor agents. Eur J Med Chem. 2015; 102:661-676.

11. Chen TC, Wu CL, Lee CC, Chen CL, Yu DS, Huang HS. Structure-based hybridization, synthesis and biological evaluation of novel tetracyclic heterocyclic azathioxanthone analogues as potential antitumor agents. Eur J Med Chem. 2015; 103:615-627.

12. Chen CL, Liu FL, Lee CC, Chen TC, Chang WW, Guh JH, Ahmed Ali AA, Chang DM, Huang HS. Ring fusion strategy for the synthesis of anthra[2,3-d]oxazole-2-thione5,10-dione homologues as DNA topoisomerase inhibitors and as antitumor agents. Eur J Med Chem. 2014; 87:30-38.

13. Chen TC, Yu DS, Huang KF, Fu YC, Lee CC, Chen CL, Huang FC, Hsieh HH, Lin JJ, Huang HS. Structure-based design, synthesis and biological evaluation of novel anthra[1,2-d]imidazole-6,11-dione homologues as potential antitumor agents. Eur J Med Chem. 2013; 69:278-293.

14. Chen CL, Chang DM, Chen TC, Lee CC, Hsieh HH, Huang FC, Huang KF, Guh JH, Lin JJ, Huang HS. Structure-based design, synthesis and evaluation of novel anthra[1,2-d]imidazole-6,11-dione derivatives as telomerase inhibitors and potential for cancer polypharmacology. Eur J Med Chem. 2013; 60:29-41.

15. Fu Y, Ong LC, Ranganath SH, Zheng L, Kee I, Zhan W, Yu S, Chow PK, Wang CH. A Dual Tracer 18F-FCH/18FFDG PET Imaging of an Orthotopic Brain Tumor Xenograft Model. PLoS One. 2016; 11:e0148123.

16. Knox C, Law V, Jewison T, Liu P, Ly S, Frolkis A, Pon A, Banco K, Mak C, Neveu V, Djoumbou Y, Eisner R, Guo AC, et al. DrugBank 3.0: a comprehensive resource for 'omics' research on drugs. Nucleic Acids Res. 2011; 39:D1035-1041.

17. Huse JT, Holland EC. Targeting brain cancer: advances in the molecular pathology of malignant glioma and medulloblastoma. Nat Rev Cancer. 2010; 10:319-331.

18. Squatrito M, Holland EC. DNA damage response and growth factor signaling pathways in gliomagenesis and therapeutic resistance. Cancer Res. 2011; 71:5945-5949.

19. Lord CJ, Ashworth A. The DNA damage response and cancer therapy. Nature. 2012; 481:287-294.

20. Hosseini A, Espona-Fiedler M, Soto-Cerrato V, Quesada R, Perez-Tomas R, Guallar V. Molecular interactions of prodiginines with the $\mathrm{BH} 3$ domain of anti-apoptotic Bcl-2 family members. PLoS One. 2013; 8:e57562.

21. Scholzen T, Gerdes J. The Ki-67 protein: from the known and the unknown. J Cell Physiol. 2000; 182:311-322.

22. Taatjes DJ, Sobel BE, Budd RC. Morphological and cytochemical determination of cell death by apoptosis. Histochem Cell Biol. 2008; 129:33-43.

23. Burma S, Chen BP, Murphy M, Kurimasa A, Chen DJ. ATM phosphorylates histone $\mathrm{H} 2 \mathrm{AX}$ in response to DNA doublestrand breaks. J Biol Chem. 2001; 276:42462-42467.

24. Chapman JR, Taylor MR, Boulton SJ. Playing the end game: DNA double-strand break repair pathway choice. Mol Cell. 2012; 47:497-510.

25. Rogakou EP, Pilch DR, Orr AH, Ivanova VS, Bonner WM. DNA double-stranded breaks induce histone H2AX phosphorylation on serine 139. J Biol Chem. 1998; 273:5858-5868.

26. Rivera M, Wu Q, Hamerlik P, Hjelmeland AB, Bao S, Rich $J \mathrm{~N}$. Acquisition of meiotic DNA repair regulators maintain genome stability in glioblastoma. Cell Death Dis. 2015; 6:e1732.

27. Shi H, Li Y, Ren X, Zhang Y, Yang Z, Qi C. A novel quinazoline-based analog induces $\mathrm{G} 2 / \mathrm{M}$ cell cycle arrest and apoptosis in human A549 lung cancer cells via a ROSdependent mechanism. Biochem Biophys Res Commun. 2017; 486:314-320.

28. Somyajit K, Basavaraju S, Scully R, Nagaraju G. ATM- and ATR-mediated phosphorylation of XRCC3 regulates DNA double-strand break-induced checkpoint activation and repair. Mol Cell Biol. 2013; 33:1830-1844. 
29. Ma Z, Yao G, Zhou B, Fan Y, Gao S, Feng X. The Chk1 inhibitor AZD7762 sensitises p53 mutant breast cancer cells to radiation in vitro and in vivo. Mol Med Rep. 2012; 6:897-903.

30. Dilley RL, Verma P, Cho NW, Winters HD, Wondisford AR, Greenberg RA. Break-induced telomere synthesis underlies alternative telomere maintenance. Nature. 2016; 539:54-58.

31. Brenner AK, Reikvam H, Lavecchia A, Bruserud O. Therapeutic targeting the cell division cycle 25 (CDC25) phosphatases in human acute myeloid leukemia--the possibility to target several kinases through inhibition of the various CDC25 isoforms. Molecules. 2014; 19:18414-18447.

32. Garcia V, Lara-Chica M, Cantarero I, Sterner O, Calzado MA, Munoz E. Galiellalactone induces cell cycle arrest and apoptosis through the ATM/ATR pathway in prostate cancer cells. Oncotarget. 2016; 7:4490-506. https://doi. org/10.18632/oncotarget.6606.

33. Tan H, Gao S, Zhuang Y, Dong Y, Guan W, Zhang K, Xu J, Cui J. R-Phycoerythrin Induces SGC-7901 Apoptosis by Arresting Cell Cycle at S Phase. Mar Drugs. 2016; 14:166.

34. Hardwick JM, Soane L. Multiple functions of BCL-2 family proteins. Cold Spring Harb Perspect Biol. 2013; 5.

35. Plati J, Bucur O, Khosravi-Far R. Apoptotic cell signaling in cancer progression and therapy. Integr Biol (Camb). 2011; 3:279-296.

36. Lin WW, Hsieh SL. Decoy receptor 3: a pleiotropic immunomodulator and biomarker for inflammatory diseases, autoimmune diseases and cancer. Biochem Pharmacol. 2011; 81:838-847.

37. Rubio-Moscardo F, Blesa D, Mestre C, Siebert R, Balasas T, Benito A, Rosenwald A, Climent J, Martinez J, Schilhabel M, Karran EL, Gesk S, Esteller M, et al. Characterization of 8p21.3 chromosomal deletions in B-cell lymphoma: TRAIL-R1 and TRAIL-R2 as candidate dosagedependent tumor suppressor genes. Blood. 2005; 106:3214-3222.

38. Arakawa Y, Tachibana O, Hasegawa M, Miyamori T, Yamashita J, Hayashi Y. Frequent gene amplification and overexpression of decoy receptor 3 in glioblastoma. Acta Neuropathol. 2005; 109:294-298.

39. Strauss LG, Conti PS. The applications of PET in clinical oncology. J Nucl Med. 1991; 32:623-48.

40. Wahl RL, Hutchins GD, Buchsbaum DJ, Liebert M, Grossman HB, Fisher S. 18F-2-deoxy-2-fluoro-D-glucose uptake into human tumor xenografts. Feasibility studies for cancer imaging with positron-emission tomography. Cancer. 1991; 67:1544-1550.

41. Monchaud D, Teulade-Fichou MP. A hitchhiker's guide to G-quadruplex ligands. Org Biomol Chem. 2008; 6:627-636.

42. Curtin NJ. DNA repair dysregulation from cancer driver to therapeutic target. Nat Rev Cancer. 2012; 12:801-817.

43. Helleday T, Petermann E, Lundin C, Hodgson B, Sharma RA. DNA repair pathways as targets for cancer therapy. Nat Rev Cancer. 2008; 8:193-204.

44. Rodriguez R, Miller KM, Forment JV, Bradshaw CR, Nikan M, Britton S, Oelschlaegel T, Xhemalce B,
Balasubramanian S, Jackson SP. Small-molecule-induced DNA damage identifies alternative DNA structures in human genes. Nat Chem Biol. 2012; 8:301-310.

45. Schipler A, Iliakis G. DNA double-strand-break complexity levels and their possible contributions to the probability for error-prone processing and repair pathway choice. Nucleic Acids Res. 2013; 41:7589-7605.

46. d'Adda di Fagagna F, Reaper PM, Clay-Farrace L, Fiegler H, Carr P, Von Zglinicki T, Saretzki G, Carter NP, Jackson SP. A DNA damage checkpoint response in telomere-initiated senescence. Nature. 2003; 426:194-198.

47. Farmer H, McCabe N, Lord CJ, Tutt AN, Johnson DA, Richardson TB, Santarosa M, Dillon KJ, Hickson I, Knights C, Martin NM, Jackson SP, Smith GC, et al. Targeting the DNA repair defect in BRCA mutant cells as a therapeutic strategy. Nature. 2005; 434:917-921.

48. Cheung-Ong K, Giaever G, Nislow C. DNA-damaging agents in cancer chemotherapy: serendipity and chemical biology. Chem Biol. 2013; 20:648-659.

49. Smith J, Tho LM, Xu N, Gillespie DA. The ATM-Chk2 and ATR-Chk1 pathways in DNA damage signaling and cancer. Adv Cancer Res. 2010; 108:73-112.

50. Kastan MB, Onyekwere O, Sidransky D, Vogelstein B, Craig RW. Participation of p53 protein in the cellular response to DNA damage. Cancer Res. 1991; 51:6304-6311.

51. Zilfou JT, Lowe SW. Tumor suppressive functions of $\mathrm{p} 53$. Cold Spring Harb Perspect Biol. 2009; 1:a001883.

52. Agami R, Bernards R. Distinct initiation and maintenance mechanisms cooperate to induce G1 cell cycle arrest in response to DNA damage. Cell. 2000; 102:55-66.

53. Agarwal ML, Taylor WR, Chernov MV, Chernova OB, Stark GR. The p53 network. J Biol Chem. 1998; 273:1-4.

54. Oltvai ZN, Milliman CL, Korsmeyer SJ. Bcl-2 heterodimerizes in vivo with a conserved homolog, Bax, that accelerates programmed cell death. Cell. 1993; 74:609-619.

55. Lai R, Jackson TL. A mathematical model of receptormediated apoptosis: dying to know why fasl is a trimer. Math Biosci Eng. 2004; 1:325-338.

56. Zhang Y, Li D, Zhao X, Song S, Zhang L, Zhu D, Wang Z, Chen X, Zhou J. Decoy receptor 3 suppresses FasL-induced apoptosis via ERK1/2 activation in pancreatic cancer cells. Biochem Biophys Res Commun. 2015; 463:1144-1151.

57. Sheikh MS, Fornace AJ Jr. Death and decoy receptors and p53-mediated apoptosis. Leukemia. 2000; 14:1509-1513.

58. Liu W, Ramagopal U, Cheng H, Bonanno JB, Toro R, Bhosle R, Zhan C, Almo SC. Crystal Structure of the Complex of Human FasL and Its Decoy Receptor DcR3. Structure. 2016; 24:2016-2023.

59. Kimura S, Kawakami T, Kawa Y, Soma Y, Kushimoto T, Nakamura M, Watabe H, Ooka S, Mizoguchi M. Bcl-2 reduced and fas activated by the inhibition of stem cell factor/KIT signaling in murine melanocyte precursors. J Invest Dermatol. 2005; 124:229-234. 